\title{
Accumulation of GC donor splice signals in mammals Alexander Churbanov ${ }^{1}$, Stephen Winters-Hilt² Eugene V Koonin*3 and Igor B Rogozin ${ }^{3}$
}

Address: ${ }^{1}$ Loyola University Medical Center, 2160 S. First Ave., Maywood, IL, 60153, USA, ${ }^{2}$ Department of Computer Science, University of New Orleans, New Orleans, LA, 70148, USA and ${ }^{3}$ National Center for Biotechnology Information NLM, National Institutes of Health, Bethesda, MD, 20894, USA

Email: Alexander Churbanov - atchourbanov@lumc.edu; Stephen Winters-Hilt - winters@cs.uno.edu; Eugene V Koonin* - koonin@ncbi.nlm.nih.gov; Igor B Rogozin - rogozin@ncbi.nlm.nih.gov

* Corresponding author

Published: 9 July 2008

Biology Direct 2008, 3:30 doi:10.1186/1745-6150-3-30

This article is available from: http://www.biology-direct.com/content/3/l/30

This is an Open Access article distributed under the terms of the Creative Commons Attribution License (http://creativecommons.org/licenses/by/2.0), which permits unrestricted use, distribution, and reproduction in any medium, provided the original work is properly cited.

\begin{abstract}
: The GT dinucleotide in the first two intron positions is the most conserved element of the $\mathrm{U} 2$ donor splice signals. However, in a small fraction of donor sites, GT is replaced by GC. A substantial enrichment of GC in donor sites of alternatively spliced genes has been observed previously in human, nematode and Arabidopsis, suggesting that GC signals are important for regulation of alternative splicing. We used parsimony analysis to reconstruct evolution of donor splice sites and inferred 298 GT > GC conversion events compared to $40 \mathrm{GC}>\mathrm{GT}$ conversion events in primate and rodent genomes. Thus, there was substantive accumulation of $\mathrm{GC}$ donor splice sites during the evolution of mammals. Accumulation of GC sites might have been driven by selection for alternative splicing.

Reviewers: This article was reviewed by Jerzy Jurka and Anton Nekrutenko. For the full reviews, please go to the Reviewers' Reports section.
\end{abstract}

\section{Findings}

In vertebrates, most of the protein-coding genes are interrupted by multiple introns that are removed at the donor and acceptor splice sites so that the adjacent exons are spliced. This process is mediated by an elaborate molecular machine, the spliceosome that consists of 5 snRNPs (small nuclear ribonucleoprotein particles) along with numerous less stably associated proteins, and is conserved throughout the eukaryotic world [1-3]. The U2 spliceosome (the major eukaryotic spliceosome) interacts with specific parts of the intron and the flanking exons to ensure accurate and efficient splicing [4]. The nucleotides at the intron termini and the adjacent nucleotides in the exons are involved in these interactions and comprise the splicing signal. The (A/C)AG|GT(A/G)AGT consensus sequence (the exon|intron boundary is shown by the vertical streak and the first two nucleotides of the intron are underlined) at the donor splice signal is complementary to the 5 ' end of U1 snRNA, and this interaction is believed to be the major requirement for splicing [5-7].

The GT dinucleotide in the first two intron positions is the most conserved element of the $\mathrm{U} 2$ donor splice signal. However, in a small fraction of donor sites $(<1 \%)$, GT is replaced by GC; in these cases, the rest of the nucleotides in the donor signal adhere more closely to the consensus sequence, apparently, compensating for the $\mathrm{T}$ to $\mathrm{C}$ substitution that is unfavorable for splicing [8-10]. This rare class of donor splice signals has been implicated in alternative splicing $[9,11,12]$. For example, the conserved $\mathrm{C}$ at 
the +2 position of the $10^{\text {th }}$ intron of the let- 2 gene which encodes one of the collagen isoforms is essential for developmentally regulated alternative splicing in the nematode C. elegans. Replacement of the GC donor signal with a moderate or strong GT signal abolishes splicing regulation and leads to excessive usage of exon 10 of let- 2 in embryos [11]. Generally, a substantial enrichment of GC donor signals in alternatively spliced genes has been observed in human, C. elegans and Arabidopsis [9,11,12].

Pairwise comparisons of GC splicing signals in the nematodes Caenorhabditis elegans and C. briggsae suggested that GC donor signals are not evolutionarily conserved in nematodes: among the 26 C. elegans GC-AG introns, only 5 had a GC-AG counterpart in C. briggsae [11]. Frequent switching between GT-AG and GC-AG introns has been reported for 5 vertebrate genomes [10]. We were interested in exploring the genome-wide evolutionary dynamics of the donor splice sites and, in particular, sought to determine whether there might be a trend toward depletion or accumulation of GC.

Genomic alignments of 8 vertebrates (chicken, opossum, dog, cow, rhesus macaque, human, mouse and rat) were extracted from the UCSC genome browser (Additional file 1) $[13,14]$ and used to map cases of GC $>$ GT and GT $>$ GC conversion to the branches of the mammalian phylogeny (Figure 1). Terminal leaves of the tree (individual genomes) are more vulnerable to the effects of sequencing errors and/or population polymorphism than internal branches [15]. Therefore, only those sites were analyzed in which the GC or GT donor signal was shared by at least two sister taxa (e.g., we assign the GC signature to the rodent clade when GC was found in both mouse and rat sequences). It was further required that either GT or GC signal was conserved in all outgroup species for which an alignment was available at the given site (the presence of the dog and cow sequences was unconditionally required). Altogether, there were 122,621 and 253 invariant GT and GC donor signals, respectively, and 656 variable sites of which 338 mapped to internal branches and were employed for the analysis of evolutionary dynamics.

The GC>GT and GT>GC conversion events were reconstructed using maximum parsimony (Figure 1). Unexpectedly, we observed a pronounced excess of GT>GC conversion over GC>GT conversion that is indicative of accumulation of GC donor splice sites in both primate and rodent genomes (Figure 1). The trend is stronger in the rodent lineage than in the primate lineage (Figure 1), an observation that is consistent with the overall fast genome evolution in rodents [16]. The apparent accumu-

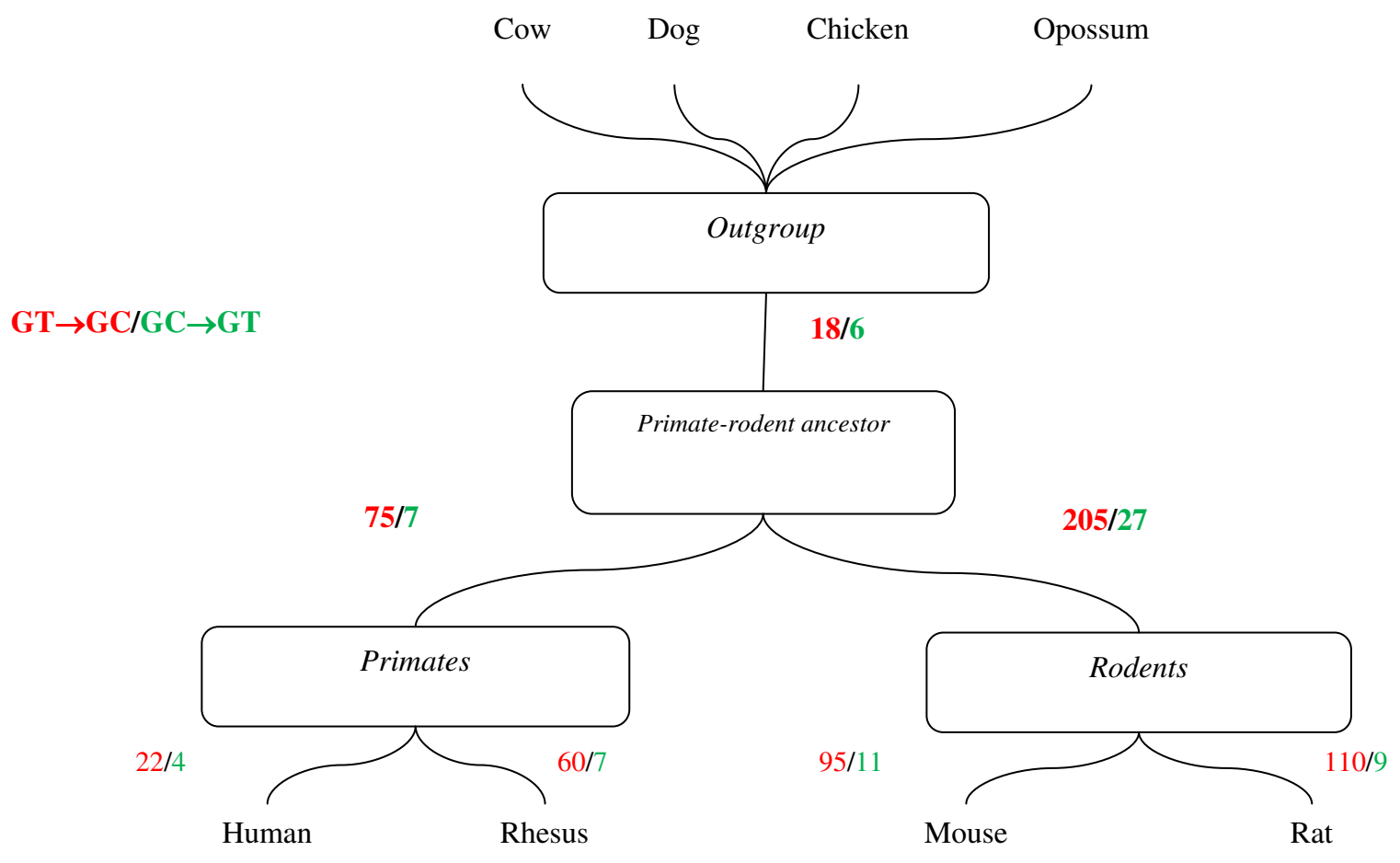

Figure I

Parsimony reconstruction of GT > GC (red) and GC > GT (green) donor signal conversion events mapped on the phylogenetic tree of 8 vertebrate species. The tree topology that includes the primate-rodent clade was from [16]. 
lation of GC donor signals was further supported by the analysis of the terminal branches of the tree although the excess of GC>GT conversions in macaque compared to human (Figure 1) could be caused by sequencing errors and/or population polymorphism. The observed excess of GT>GC conversions was robust with respect to the composition of the outgroup species set (Additional file 2).

The observed excess of GT>GC conversions hardly can be explained by a nucleotide substitution bias. It has been repeatedly shown that mammalian genomes have a tendency to become more AT-rich [17-19]. Even if one assumes that, due to unknown reasons, this trend is reversed in the donor sites so that $\mathrm{T}$ to $\mathrm{C}$ substitutions are twice as frequent as $\mathrm{C}$ to $\mathrm{T}$ substitutions, such a bias would not account for the observed excess of GT>GC conversion events $\left(\mathrm{P}<10^{-10}\right.$ according to the $\chi^{2}$ test for pooled conversion events).

Considering that mutational bias did not seem to be a plausible cause of the observed accumulation of GC donor sites, it seems most likely that this trend has to do with the involvement of GC sites in alternative splicing that is widespread and essential in mammals $[9,11,12]$. As GT>GC conversion can substantially alter the pattern of alternative splicing [11], these changes might become beneficial and eventually would be fixed in the population. Thus, positive selection could be a plausible explanation for the observed accumulation of GC in donor sites. However, an even more plausible scenario would involve evolution of a strong splice site context that would allow neutral fixation of GC sites. The neutrally fixed GC sites, then, could be recruited for alternative splicing and thus would become subject to purifying selection forbidding the reverse GC>GT conversion.

\section{Competing interests}

The authors declare that they have no competing interests.

\section{Authors' contributions}

AC performed sequence comparisons, SWH contributed to the interpretation of the results, AC and IBR contributed to the analysis of the results and wrote the initial draft of the manuscript, IBR and EVK incepted the study, contributed to the analysis of the results and wrote the final manuscript, all authors edited and approved the final version.

\section{Reviewers' comments \\ Reviewer's report I: Jerzy Jurka, Genetic Information Research Institute}

This paper reports the relatively straightforward observation that GC donor splice sites tend to accumulate during evolution of mammals. However, the suggestion of selection for alternative splicing would be more convincing if the authors could demonstrate the GC accumulation separately in AT-rich and GC-rich genomic regions in mammals, where the dynamics of GT replacement by GC may be different.

\section{Authors' response \\ We appreciate the suggestion that the dynamics of GC accumu- lation could depend on the base composition in the respective regions of the mammalian genomes.}

So we performed a crude comparison of the occurrence of GC donor sites and the rates of donor site conversion in AT-rich and GC-rich regions. Table 1shows that, although there was a statistically significant excess of GC donor sites in GC-rich regions, there was only a marginal, not statistically significant difference between the corresponding rates of donor site conversions. Thus, it appears that the accumulation of GC donor sites described here does not strongly depend on the nucleotide composition of the corresponding genomic regions.

\section{Reviewer's report 2: Anton Nekrutenko, Pennsylvania State University}

In this discovery note authors point out accumulation of non- canonical GC donor splice signals in mammals, against the previously observed nucleotide substitution bias. They provide a convincing explanation suggesting that GT->GC conversion may be beneficial for mammals as it creates additional possibilities for alternative splicing events. In my opinion these observations provide a platform for launching more detailed investigation of alternative splicing through comparative genomics and raise numerous interesting question (e.g., are any of the GC sites overlap with known SNPs?). Thus publication of this

Table I: GT and GC donor splice sites and conversion events in AT-rich and GC-rich regions ${ }^{\mathrm{a}}$

\begin{tabular}{|c|c|c|c|}
\hline Splice sites/conversion events & $\% A+T>50 \%$ & $\% A+T<50 \%$ & $\mathrm{P}_{\text {Fisher }} / \mathrm{GT}^{\mathrm{b}}$ \\
\hline Total number of donor splice sites(\%) & $51798(100)$ & $71396(100)$ & \\
\hline GT & $51575(99.57)$ & $71028(99.48)$ & \\
\hline GC & $88(0.17)$ & $165(0.23)$ & 0.02 \\
\hline GT>GC & $\mathrm{II} 3(0.22)$ & $185(0.26)$ & 0.15 \\
\hline $\mathrm{GC}>\mathrm{GT}$ & $22(0.04)$ & $18(0.03)$ & 0.11 \\
\hline
\end{tabular}

aAT content was estimated in \pm 100 base pair regions surrounding donor splice sites

bStatistical significance was estimated by comparing the respective values with the number of GT sites using Fisher's two-tailed test 
note will appeal to a broad evolutionary genomics community.

On a technical side the authors used a rather complex procedure for retrieving splice sites from TBA alignments. Instead, this can be easily and quickly done using Galaxy system:

http://main.g2.bx.psu.edu

as explained here:

\section{http://g2.trac.bx.psu.edu/wiki/MAFanalysis}

\section{Authors' response}

We appreciate the reviewer pointing out the utility of the Galaxy platform and hope to exploit Galaxy in future genome analyses.

\section{Additional material}

\author{
Additional file 1 \\ Materials and Methods. \\ Click here for file \\ [http://www.biomedcentral.com/content/supplementary/1745- \\ 6150-3-30-S1.doc]

\section{Additional file 2} \\ Parsimony reconstruction of GT > GC and GC > GT donor signal conver- \\ sion events for different sets of outgroup species. \\ Click here for file \\ [http://www.biomedcentral.com/content/supplementary/1745- \\ 6150-3-30-S2.doc]
}

\section{Acknowledgements}

The research of IBR and EVK is supported by the Department of Health and Human Services intramural program (NIH, National Library of Medicine). The research of AC and SWH is supported by an NIH National Library of Medicine K-22 award (K22LM008794), and via private funding from the Research Institute for Children, New Orleans.

\section{References}

I. Jurica MS, Moore MJ: Pre-mRNA splicing: awash in a sea of proteins. Mol Cell 2003, I 2(I):5-14.

2. Nilsen TW: The spliceosome: the most complex macromolecular machine in the cell? Bioessays 2003, 25(12): I I47-I I 49.

3. Collins L, Penny D: Complex spliceosomal organization ancestral to extant eukaryotes. Mol Biol Evol 2005, 22(4): I053- 1066.

4. Patel AA, Steitz JA: Splicing double: insights from the second spliceosome. Nat Rev Mol Cell Biol 2003, 4(I 2):960-970.

5. Rosbash M, Seraphin B: Who's on first? The UI snRNP-5' splice site interaction and splicing. Trends Biochem Sci 1991, 16(5): $187-190$.

6. Du H, Rosbash M: The UI snRNP protein UIC recognizes the 5' splice site in the absence of base pairing. Nature 2002, 419(6902):86-90.

7. Carmel I, Tal S, Vig I, Ast G: Comparative analysis detects dependencies among the 5' splice-site positions. Rna 2004, I 0(5):828-840.
8. Burset M, Seledtsov IA, Solovyev VV: Analysis of canonical and non-canonical splice sites in mammalian genomes. Nucleic Acids Res 2000, 28(21):4364-4375.

9. Thanaraj TA, Clark F: Human GC-AG alternative intron isoforms with weak donor sites show enhanced consensus at acceptor exon positions. Nucleic Acids Res 200I, 29(I2):258I-2593.

10. Abril JF, Castelo R, Guigo R: Comparison of splice sites in mammals and chicken. Genome Res 2005, I5(I): III-II9.

II. Farrer T, Roller AB, Kent WJ, Zahler AM: Analysis of the role of Caenorhabditis elegans GC-AG introns in regulated splicing. Nucleic Acids Res 2002, 30( I5):3360-3367.

12. Campbell MA, Haas BJ, Hamilton JP, Mount SM, Buell CR: Comprehensive analysis of alternative splicing in rice and comparative analyses with Arabidopsis. BMC Genomics 2006, 7:327.

13. Blanchette M, Kent WJ, Riemer C, Elnitski L, Smit AF, Roskin KM, Baertsch R, Rosenbloom K, Clawson H, Green ED, Haussler D, Miller $\mathrm{W}$ : Aligning multiple genomic sequences with the threaded blockset aligner. Genome Res 2004, 14(4):708-7/5.

14. Kuhn RM, Karolchik D, Zweig AS, Trumbower H, Thomas DJ, Thakkapallayil A, Sugnet CW, Stanke M, Smith KE, Siepel A, Rosenbloom KR, Rhead B, Raney BJ, Pohl A, Pedersen JS, Hsu F, Hinrichs AS, Harte RA, Diekhans M, Clawson H, Bejerano G, Barber GP, Baertsch R, Haussler D, Kent WJ: The UCSC genome browser database: update 2007. Nucleic Acids Res 2007, 35(Database issue):D668-73.

15. Rogozin IB, Wolf YI, Carmel L, Koonin EV: Ecdysozoan clade rejected by genome-wide analysis of rare amino acid replacements. Mol Biol Evol 2007, 24(4): 1080-1090.

16. Thomas JW, Touchman JW, Blakesley RW, Bouffard GG, BeckstromSternberg SM, Margulies EH, Blanchette M, Siepel AC, Thomas PJ, McDowell JC, Maskeri B, Hansen NF, Schwartz MS, Weber RJ, Kent WJ, Karolchik D, Bruen TC, Bevan R, Cutler DJ, Schwartz S, Elnitski L, Idol JR, Prasad AB, Lee-Lin SQ, Maduro VV, Summers TJ, Portnoy ME, Dietrich NL, Akhter N, Ayele K, Benjamin B, Cariaga K, Brinkley CP, Brooks SY, Granite S, Guan X, Gupta J, Haghighi P, Ho SL, Huang MC, Karlins E, Laric PL, Legaspi R, Lim MJ, Maduro QL, Masiello CA, Mastrian SD, McCloskey JC, Pearson R, Stantripop S, Tiongson EE, Tran JT, Tsurgeon C, Vogt JL, Walker MA, Wetherby KD, Wiggins LS, Young AC, Zhang LH, Osoegawa K, Zhu B, Zhao B, Shu CL, De Jong PJ, Lawrence CE, Smit AF, Chakravarti A, Haussler D, Green P, Miller W, Green ED: Comparative analyses of multi-species sequences from targeted genomic regions. Nature 2003, 424(6950):788-793.

17. Pozdniakov MA, Rogozin IB, Babenko VN, Kolchanov NA: Neighboring base effect on emergence of spontaneous mutations in human pseudogenes. Dokl Akad Nauk 1997, 356(4):566-568.

18. Petrov DA, Hartl DL: Patterns of nucleotide substitution in Drosophila and mammalian genomes. Proc Natl Acad Sci U S A 1999, 96(4): 1475-| 479.

19. Jiang C, Zhao Z: Directionality of point mutation and 5-methylcytosine deamination rates in the chimpanzee genome. BMC Genomics 2006, 7:316.

Publish with Biomed Central and every scientist can read your work free of charge

"BioMed Central will be the most significant development for disseminating the results of biomedical research in our lifetime. "

Sir Paul Nurse, Cancer Research UK

Your research papers will be:

- available free of charge to the entire biomedical community

- peer reviewed and published immediately upon acceptance

- cited in PubMed and archived on PubMed Central

- yours - you keep the copyright

BiolMedcentral 